\title{
8
}

\section{A Device for the Sonic Tracking of Large Fishes}

\author{
George A. Bass \& Mark Rascovich
}

The American Museum of Natural History

(Plates I \& II; Text-figures 1-5)

\section{INTRODUCTION}

S INCE a device which would enable one to follow the movements of unconfined and untethered fishes would have value in studies concerned with both their short term movements and their larger migratory travels, efforts were made to develop such an instrument. A variety of possible solutions was considered, finally settling on some sonic means as potentially most capable of practical development. The sonic tracking transmitter, to be attached to a fish, and the receiver, to be carried by a boat fast enough to keep the fish under study within range, comprise the system as developed. Specifications of the system and the results of trials on fishes are given.

We wish to express our appreciation to the following: Dr. Sidney R. Galler, Head, Biology Section, Office of Naval Research, for advice and counsel; Mr. Frank Mather, III, Research Fellow, Woods Hole Oceanographic Institution, for fisheries and fish tagging information; $\mathrm{Mr}$. Frank M. Vargo, Chief Engineer, Airtronics International Corporation, for electronic development and applications; Mr. John Rybovich, Rybovich Boat Co., and Mr. Jack Hargrave, Naval Architect, for marine design; Capt. C. C. Anderson, Palm Beach, Florida, operator of the tracking boat, who was of great assistance during the tests; and the management of the Lerner Marine Laboratory for facilities in connection with preliminary tests.

The development of this system has been supported in part by O. N. R. Contract Nonr 552(04) NR 301-257 held by C. M. Breder, Jr., of The American Museum of Natural History, and in part by the George A. Bass Fund.

\section{System Specifications}

The transmitter consists of an aluminum cylinder, $21 / 2$ " o.d. $\times 10^{1 / 4}$ " long, with a barium titanate transducer molded into one end. See Text-fig. 1. This transmitting package is designed to withstand depths of $900^{\prime}$ and weighs 34 ounces in seawater. The tracking signal radiated by the transmitter consists of pulsed ultrasonic energy with a frequency of $38 \mathrm{KC}$ and a pulse duration of 50-100 milliseconds; the repetition rate is one pulse every two seconds. Power is provided by a 13 -volt mercury battery with a life of 150 hours and provides 12 watts input to the transducer. It is streamlined, painted a mat gray-green, and is attached to the fish by means of barbed prongs with the transducer facing aft for proper tracking configuration. See Plate I, Fig. 1, and Text-fig. 2 for the schematic.

Receiving transducers aboard the tracking vessel are two in number, of barium titanate, and mounted adjacent to a pre-amplifier in a tenfoot-long hydrofoil boom fabricated out of aluminum. This boom is faired out over its lower six-foot portion to provide a smooth hydrofoil section over its submerged part. The transducers are molded individually in rubber and mounted with the axis horizontal and located at 90 degrees with respect to each other. Sound-absorbing material surrounds each transducer, leaving only the front face exposed to couple with seawater. Liquid rubber was used as an over-all finishing coat to provide additional protection and a smooth exterior surface. The transducers are sufficiently unidirectional in their response and are connected to the input of the dual channel, low noise, narrow band pre-amplifier. To 


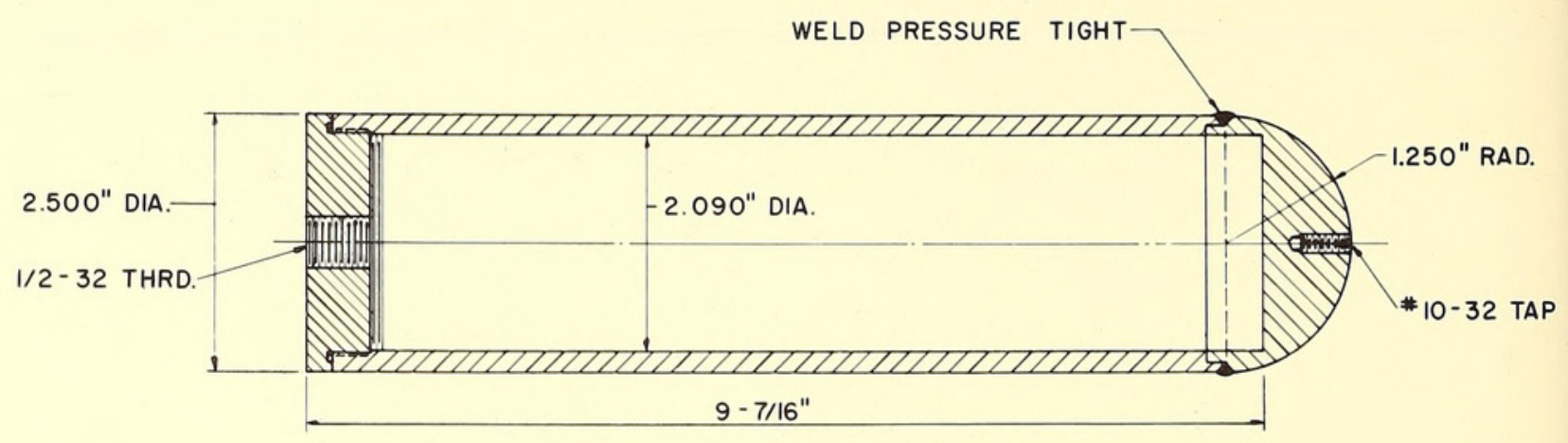

TeXT-Fig. 1. Construction of the submersible capsule, intended for depths up to 150 fathoms.

further reduce extraneous noise at this point, the pre-amplifier has its own battery power supply carried in the upper portion of the boom. The pre-amplifier has a usable input sensitivity of 2 microvolts with low impedance outputs to match the $50 \mathrm{ohm}$ coaxial cable used to connect it to the receiver unit on the bridge or in the cockpit. When in operation, the unit is mounted vertically from the bow of the boat, usually through a strong pulpit, and secured by welded metal bracing, its lower end submerged ahead of the bow-wave and 4-6 feet below the surface. All fittings securing it to the boat are gasketed with rubber insulation to guard against ship noise and vibration. See Plate I, Figs. 2 and 5, and Text-fig. 3 for the schematic.

The shipboard receiver is housed in a spraytight metal cabinet with a gasketed, removable lid. All operating controls are mounted on a subpanel accessible when the lid is removed. A compartment is provided for a 12-volt battery which powers the unit, and for accessories. The receiver consists of a dual channel, narrow band amplifier with low impedance output to match the pre-amplifier. It is completely shielded to minimize pickup from the boat's electrical system. The main operating controls consist of a "Power On" switch, dual ganged "Gain" control, "Tone" control, "Range" sensitivity control, "Direction" sensitivity control, and "Volume" control. A visual signal read-out is provided by a zero center meter which gives directional information by deflecting either left or right; a second meter gives an indication of range by measuring strength of signal. Aural read-out is obtained from a set of stereo head-

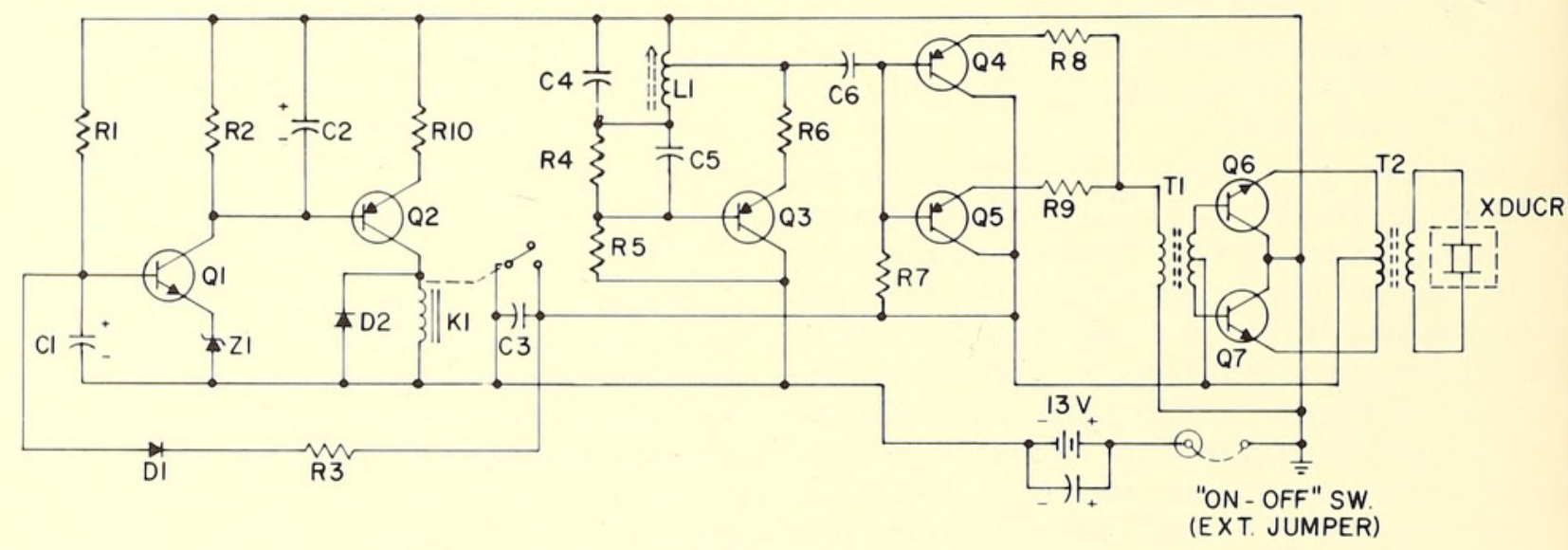

TeXT-FIG. 2. Schematic of the transmitter.

\section{COMPONENT PARTS LIST}

$\mathrm{C} 1$ - Subminiature electrolytic capacitor, $10 \mathrm{mfd} / 15 \mathrm{v}$

C2 - Subminiature electrolytic capacitor, $50 \mathrm{mfd} / 15 \mathrm{v}$

C3, C6 - Molded plastic capacitor, $.033 \mathrm{mfd} / 50 \mathrm{v}$.

C4 - Molded plastic capacitor, $.0047 \mathrm{mfd} / 50 \mathrm{v}$.

C5 - Molded mica capacitor, $100 \mathrm{mmfd} / 200 \mathrm{v}$.

C7 - Subminicture electrolytic capacitor, $200 \mathrm{mfd} / 15 \mathrm{v}$.

D1 - Silicon diode, $100 \mathrm{MA} / 30 \mathrm{v}$.

D2 - Silicon diode, $500 \mathrm{MA} / 50 \mathrm{v}$

K1 - Sensitive relay, S.P.D.T., 6V Coil.

L1 - Adjustable inductor, $4.0 \mathrm{mh}$.

L1 - Adjustable inductor, $4.0 \mathrm{mh}$.
Q1 - Silicon NPN transistor, $200 \mathrm{mw}$.

Q1 - Silicon NPN transistor, $200 \mathrm{mw}$.

Q2 through Q5 - Germanium PNP transistor, $200 \mathrm{mw}$

Q6, Q7 - Silicon NPN transistor, 10w.

R1, R5 - Molded composition resistor, $100 \mathrm{Kohm} / 1 / 2 \mathrm{w}$
R2 - Molded composition resistor, $10 \mathrm{Kohm} / 1 / 2 \mathrm{w}$.

R3, R7 - Molded composition resistor, $4.7 \mathrm{Kohm} / 1 / 2 \mathrm{w}$.

$\mathrm{R} 4$ - Molded composition resistor, $22 \mathrm{Kohm} / 1 / 2 \mathrm{w}$.

R6 - Molded composition resistor, $100 \mathrm{ohm} / 1 / 2 \mathrm{w}$.

R8, R9 - Molded composition resistor, $47 \mathrm{ohm} / 1 / 2 \mathrm{w}$.

R 10 - Molded composition resistor, $12 \mathrm{ohm} / 1 / 2 \mathrm{w}$.

T1 - Driver transformer, 200ohm Pri. Imp., 800ohm CT Sec.

T2 - Output transformer, 48ohm CT Pri. Imp., 800ohm Sec.

Xducer (Transducer) - Barium titanate, cylindrical, molded in rubber.

$\mathrm{Z} 1$ - Zener diode, $7.5 \mathrm{v} / 1 \mathrm{w}$. 


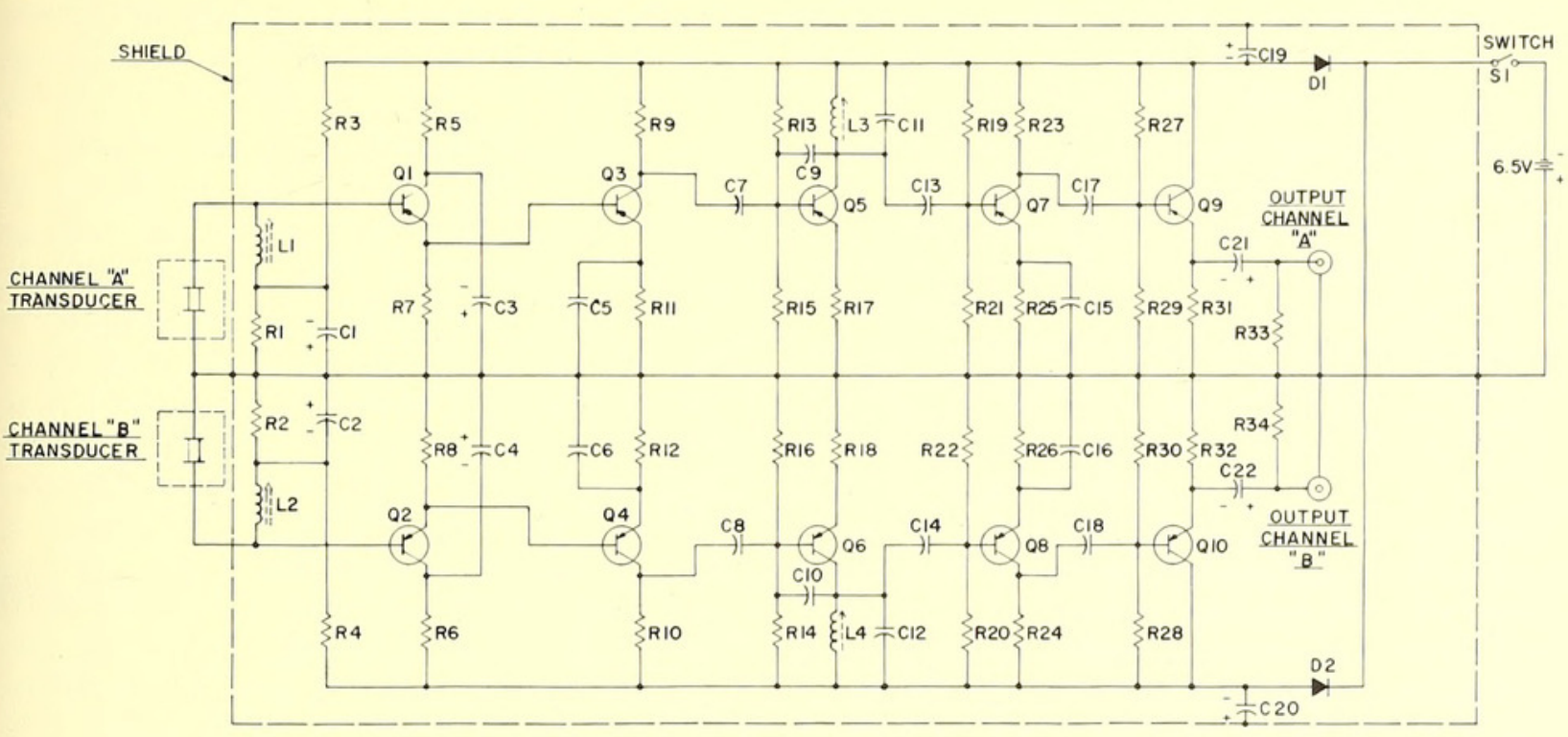

TeXT-FIG. 3. Schematic of the underwater part of the receiver.

\section{COMPONENT PARTS LIST}

C1, C2 - Subminiature electrolytic capacitor, $10 \mathrm{mfd} / 3 \mathrm{v}$. C3, C4 - Subminiature electrolytic capacitor, $10 \mathrm{mfd} / 15 \mathrm{v}$ C5 through C8 \& C13 through C18 - Ceramic disc capacitor, $0.1 \mathrm{mfd} / 50 \mathrm{v}$.

C9, C10 - Molded mica capacitor, $500 \mathrm{mmfd} / 200 \mathrm{v}$.

C11, C12 - Molded plastic capacitor, .008 mfd/50v.

C19, C20 - Subminiature electrolytic capacitor, $100 \mathrm{mfd} / 15 \mathrm{v}$ C21, C22 - Subminiature electrolytic capacitor, $2 \mathrm{mfd} / 15 \mathrm{v}$.

$\mathrm{D} 1, \mathrm{D} 2-\mathrm{Silicon}$ diode, $500 \mathrm{MA} / 50 \mathrm{v}$.

L1, L2 - Adjustable inductor, $2.5 \mathrm{mh}$.

L3, L4 - Adjustable inductor, $2.0 \mathrm{mh}$.

Q1 through Q10 - Germanium PNP transistors, $200 \mathrm{mw}$

R1, R2, R17, R18, R25, R26, R33, R34 - Molded composition resistor, $1 \mathrm{Kohm} / 1 \frac{1}{2} \mathrm{w}$.

phones and supplements that given by meter. See Plate I, Fig. 3, and Text-fig. 4 for the schematic.

The system, shown in Text-fig. 5 in block diagram form, is designed primarily for use on small boats of the sport fishing type, the one used for all testing and tracking having been only 32 feet over-all. Self-contained power makes operation independent of the boat's electrical supply.

A useful accessory for emergency use when the signal is either lost or too marginal for an accurate bearing, is the hand-held "snifter." This is a single-transducer hydrophone mounted on one end of a 9-foot-long. 11/2" aluminum tube, a power supply, switch, and pre-amplifier boxed in the opposite end, and connected to the shipboard receiver by a length of coaxial cable. See Plate I, Fig. 4. This lightweight unit can be held over the side of the boat with the transducer submerged, and rotated by hand when the tracking vessel is stopped; it has proved to be extremely sensitive. For inshore tracking in bays or estuaries, .it can undoubtedly be used as the main receiving transducer from small skiffs and outboards if neither speed nor wave action is of any consequence.
R3, R4 - Molded composition resistor, $22 \mathrm{Kohm} / 1 / 2 \mathrm{~W}$.

R5, R6, R9, R10, R23, R24 - Molded composition resistor, $2.2 \mathrm{Kohm} / 1 / 2 \mathrm{w}$.

R7, R 8 - Molded composition resistor, $220 \mathrm{ohm} / 1 / 2 \mathrm{w}$,

R11, R12, R31, R32 - Molded composition resistor, 100$\mathrm{ohm} / 1 / 2 \mathrm{w}$.

$\mathrm{R} 13, \mathrm{R} 14, \mathrm{R} 19, \mathrm{R} 20$ - Molded composition resistor, 82Kohm/1/2w.

R15, R16, R21, R22, R29, R30-Molded composition resistor, $10 \mathrm{Kohm} / 1 / 2 \mathrm{~W}$

R27, R28-Molded composition resistor, $68 \mathrm{Kohm} / 1 / 2 \mathrm{w}$.

Xducer (Transducer) - Barium titanate, cylindrical, molded in rubber.

The over-all performance of the present system is satisfactory for a tracking range of $1 \frac{1 / 2}{2}$ miles through sea-state 3 and at a speed of up to 10 knots. At reduced speed with subsequent reduction in extraneous noise in the system, the range quickly builds up to better than 2 miles. The range may be increased still further to approximately 10 miles by boosting the power output of the transmitter, but this will, of course, reduce its life.

\section{Equipment Development}

Development of this tracking system was started in 1959 and continues through the present. Prior to that time, limited sonic tracking of salmon had been accomplished in rivers and estuaries over short ranges and time periods. See, for instance, Trefethen and colleagues. ${ }^{1}$ Marine tracking under oceanic conditions, involving far greater distances and durations, presented a different and more complex set of problems, the solution of one often compromising the solution of another. While the sonic tag

${ }^{1}$ Trefethen, P. S. 1956. U. S. Fish and Wildlife Serv., Special Sci. Rept. Fisheries No. 179, 11 pp.

Trefethen, P. S., J. W. Dudley \& M. R. Smith. 1957. Electronics, Vol. 30, No. 4, pp. 156-160. 


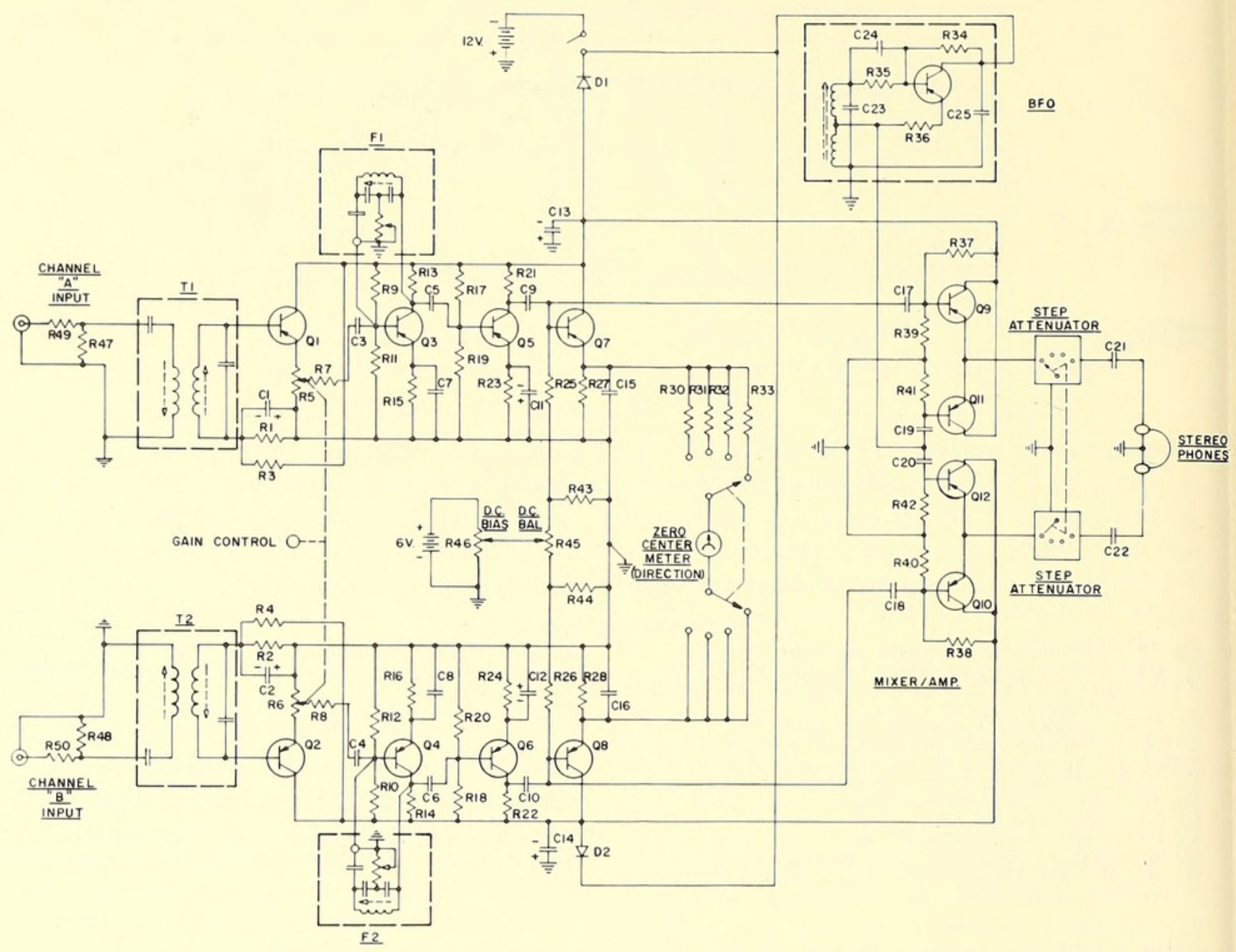

TeXt-FIG. 4. Schematic of the shipboard part of the receiver.

\section{COMPONENT PARTS LIST}

BFO - Beat frequency oscillator, adjustable $36 \mathrm{KC}$ to $40 \mathrm{KC}$. $\mathrm{C} 1, \mathrm{C} 2-$ Subminiature electrolytic capacitor, $5 \mathrm{mfd} / 15 \mathrm{v}$. C3 through C6, C9, C10, C24, C25 - Ceramic disc capacitor, $0.1 \mathrm{mfd} / 50 \mathrm{v}$

C7, C8 - Molded plastic capacitor, $.03 \mathrm{mfd} / 50 \mathrm{v}$.

C11, C12 - Subminiature electrolytic capacitor, $10 \mathrm{mfd} / 15 \mathrm{v}$. C13. C14 - Subminiature electrolytic capacitor, $100 \mathrm{mfd} / 15 \mathrm{v}$. C15, C16 - Molded plastic capacitor, .04 mfd/50v.

C17, C18 - Molded plastic capacitor, .005 mfd/50v.

C19, C20 - Molded mica capacitor, $500 \mathrm{mmfd} / 200 \mathrm{v}$.

C19, C20 - Molded mica capacitor, $500 \mathrm{mmfd} / 200 \mathrm{v}$.

C21, C22 - Molded plastic capacitor, $1.0 \mathrm{mfd} / 50 \mathrm{v}$. Molded plastic capacitor, $.0047 \mathrm{mfd} / 50 \mathrm{v}$.

C23 - Molded plastic capacitor, .0047
D1, D2 - Silicon diode, $500 \mathrm{MA} / 50 \mathrm{v}$.

F1, F2 - Filter, Bridged "T", Adjustable $36 \mathrm{KC}$ to $40 \mathrm{KC}$, L1 - Adjustable inductor, $4.0 \mathrm{mh}$.

Q1 through Q13 - Germanium PNP transistors, $200 \mathrm{mw}$.

R1, R2, R7, R8, R11, R12, R19, R20, R25, R26, R39 through $\mathrm{R} 44$ - Molded composition resistor, $10 \mathrm{Kohm} / 1 / 2 \mathrm{w}$.

was designed for large fish of $250 \mathrm{lbs}$. and over, miniaturization of the transmitting unit remained difficult because anything less than 150 hours of transmitter life was not considered practical for the project. Mercury batteries provided a solution to this problem. In general, however, less difficulty was experienced with the transmitter than with the receiving components of the system and its design has remained the same since 1961 .

Obviously the system described herein is to be considered a step in the rapidly moving fields of electronics and underwater supersonics which,
R3, R4, R9, R10, R34, R37, R38 - Molded composition resistor, $100 \mathrm{Kohm} / 1 / 2 \mathrm{~W}$.

R5, R6 - Dual concentric potentiometer, $1 \mathrm{Kohm} / 1 / 2 \mathrm{w}$.

R13, R14, R27, R28, R36 - Molded composition resistor $1 \mathrm{Kohm} / 1 / 2 \mathrm{w}$.

R15, R16, R23, R24, R47, R48 - Molded composition resistor, $100 \mathrm{ohm} / 1 / 2 \mathrm{~W}$.

R17. R18 - Molded composition resistor, $47 \mathrm{Kohm} / 1 / 2 \mathrm{w}$.

R21, R22 - Molded composition resistor, $470 \mathrm{ohm} / 1 / 2 \mathrm{w}$.

R30 - Molded composition resistor, $18 \mathrm{Kohm} / 1 / 2 \mathrm{w}$.

$\mathrm{R} 31$ - Molded composition resistor, $8.2 \mathrm{Kohm} / 1 / 2 \mathrm{w}$.

R31 - Molded composition resistor, $8.2 \mathrm{Kohm} / 1 / 2 \mathrm{w}$.

$\mathrm{R} 32$ - Molded composition resistor, $3.9 \mathrm{Kohm} / 1 / 2 \mathrm{~W}$.

R 35 - Molded composition resistor, $22 \mathrm{Kohm} / 1 / 2 \mathrm{w}$.

R45, R46 - Potentiometer, $10 \mathrm{Kohm} / 1 / 2 \mathrm{w}$.

R49, R50 - Molded composition resistor, $47 \mathrm{ohm} / 1 / 2 \mathrm{w}$.

T1. T2 - Input transformer, adjustable $36 \mathrm{KC}$ to $40 \mathrm{KC}$.

it is hoped, will eventually lead to much more sophisticated instrumentation. The present model provides no direct data on the depth at which the fish may be located. This could be accomplished by introducing some pressure transducer approximately affecting the pulse rate or other feature of the signal, but only at the expense of greater bulk. The size of the transmitter could be reduced but at the cost of shortening its life. This may be of more importance than generally thought, since Clancy $(1963)^{2}$ has shown that

${ }^{2}$ Clancy, D. W. 1963. Jour. Fish. Res. Bd. Canada, Vol. 20, No. 4, pp. 969-981. 
even a one-half-inch disc tag reduces swimming speed in six-inch salmon fingerlings by about $50 \%$.

Early models of the system were tested at sea by towing an activated transmitter at various depths and speeds while a tracking vessel checked out the receiver system. By this method, weaknesses in the housing and handling of the receiving transducers quickly became evident and a number of methods and designs were tested and rejected. While excellent range characteristics could be obtained when either stopped or operating at very low speeds in a flat sea, ambient noises with concurrent loss of range quickly built up when speed and sea-state increased. The ship's noise proved by far the most vexing engineering problem. Light, easily handled "rods" supporting the transducer housings were invariably too fragile and subject to highfrequency vibrations when under way. Freetowed underwater vehicles of delta-wing design were too difficult to handle with the gear available on a small boat and also proved unsatisfactory in tight maneuvering. The fixed, rigid hydrofoil boom used in the tuna tests of MayJune, 1963, evolved from several earlier models and turned out to be the most dependable for both sturdiness and "silent operation." However, it is not considered the final solution and presents difficulties which will be discussed later.

The signal's frequency of $38 \mathrm{KC}$, presumably beyond the range of fish hearing, was chosen because (at the time) it was compatible with available electronic components, and tests made in the fish pens at the Lerner Marine Laboratories caused no apparent reactions on available marine species, even when radiated at powers above $10 \mathrm{KW}$. Lower frequencies will, of course, have greater range and penetration, but the power required and the increased size of the transducer made their use impractical in this case.

\section{Trials ON Fishes}

The following protocol of tests made directly on fishes indicates both the manner in which it was possible to handle the fishes and the type of information they may be expected to produce. Three species were used: Carcharhinus sp., probably C. milberti (Müller \& Henle); Sphyrna zygaena (Linnaeus); and Thunnus thynnus (Linnaeus).

\section{Trials on Carcharhinus}

An estimated 300-pound shark was released with the sonic capsule off Jupiter Inlet, Florida, in less than 30 fathoms. It was tracked for four hours. After an initial run of about one-quarter mile it settled down to cruising in various depths between 15 and 21 fathoms. It followed a crisscross pattern in an area of about one square mile at a speed of about three knots. The area of this activity could well represent its normal home territory. The distance from shore varied between four and six miles.

\section{Trials on Sphyrna}

An estimated 300- to 350-pound hammerhead was released with a transmitter three miles off Palm Beach, Florida, over 60 fathoms, on April 16. After some initial meandering, the shark headed in a generally easterly direction, at a speed averaging about three knots. It was followed for two hours, the tracking boat's position then being nine miles east-northeast of Palm Beach Inlet.

\section{Trials on Thunnus}

All tuna work was carried out during late May, 1963, out of Cat Cay, Bahamas. Sonic capsules were attached to three tuna.

An individual of about 400 lbs. was caught approximately five miles west of Gun Cay on

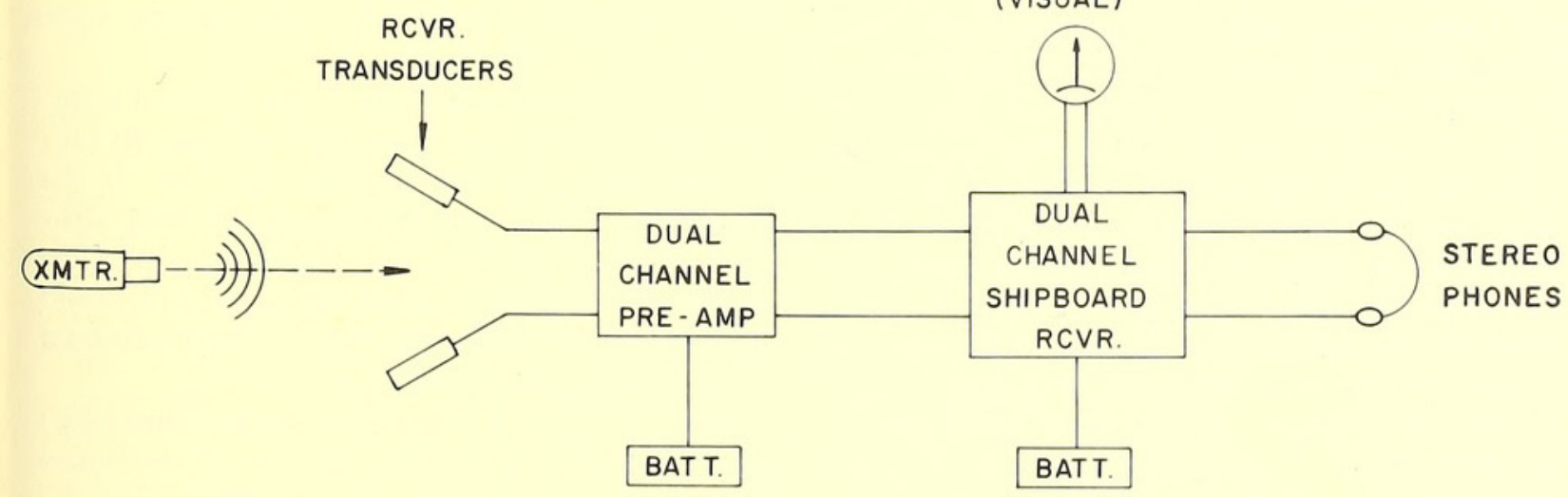


May 24 in about 120 fathoms. It was released immediately after the transmitter was attached and sounded at once. Visual observation was possible only for a few seconds when the tuna was seen diving at high speed with a white-tip shark, Carcharhinus longimanus (Poey)?, in close pursuit. The tracking boat had been waiting some 500 yards away and immediately picked up a strong tracking signal. The tuna evidently escaped the shark because, after its initial fast run, it began swimming deep on an erratic course which generally followed wide circles of roughly half-mile diameter. This pattern showed a northerly drift at first, but after about fifty minutes the fish moved in a generally southwesterly direction. Its speed varied a great deal, between 3-12 knots, with frequent deviations from its course, all of which made tracking somewhat difficult. However, although the signal occasionally became marginal, it was possible to follow the fish. Tracking of this particular tuna lasted one hour and seven minutes and was terminated because of a collapse of the hydrofoil boom. This was caused by an unexpected wave, possibly a wake from one of the many fishing cruisers speeding about the area, which damaged the supporting bracing of the hydrofoil boom.

A second tuna of about the same size as the first, captured three miles northwest of Sand Cay in about 15 fathoms, was similarly released on June 10, except that no sharks were seen. The tracking boat was approximately 300 yards away and picked up a strong signal. It was easily followed as the fish headed westerly toward the Gulf Stream, about a half-mile distant, at approximately seven knots. After about seven minutes the signal stopped abruptly. There was no fading, as would be expected if the fish had merely outdistanced the boat.

A third tuna was released with a transmitter about two miles west of Little Cat Cay and behaved in a closely similar manner, except that it showed a greater flurry of activity at the release and then quickly settled westerly toward the Gulf Stream, about three miles away. Once it reached deep water, it changed its course to a steady southwest. The speed remained fairly high, between 8 and 10 knots, with occasional faster bursts. After two hours and fifteen minutes, over 20 miles offshore, the fish was being followed at distances which varied from 500 yards to $1 \frac{1}{2}$ miles through sea-state 3 . At no time did the signal even become marginal and there was never any question as to the location of the tuna ahead of the boat. Undoubtedly tracking could have been continued for considerable time and distance, but oncoming darkness, the distance from Cat Cay and the fact that the boat was not suited for extended stays at sea caused a termination of the trail at this point. The signal continued to be heard for more than ten minutes after the course had been reversed.

\section{Discussion}

The tracking experiments on tuna off Cat Cay and of two sharks in Florida waters, and some twenty-five "sled tests" with towed tags, have proved the feasibility of the basic system. In its present stage of development it can be useful in gathering ecological data and can contribute to the study of behavior patterns of marine animals. The following details concern various items which it is thought would be of use to anyone undertaking similar developments.

Method of Housing and Handling the Receiving Transducers.-While the present design of a hydrofoil boom carried ahead of the bow wave worked satisfactorily, it had certain inherent limitations. Naturally, extremely rugged bracings are necessary for deep-sea work. These restrict the maneuverability of the boat to some extent. For safety reasons, the entire unit must be easily and quickly detachable. This model was fixed in position, but a turnable one would be much better, although vastly complicating the design. Through-the-hull types of retractable and trainable housings have been considered and might well be more suitable for permanent installations, but the hull noise factor would be a critical consideration. For long range deep-sea tracking, it is probable that a combined system of fixed installation and towed vehicle will prove to be the most practical.

The loss of the second tuna was caused by the failure of the boom bracings, which originally were made of aluminum. These were replaced by channel iron.

Recording.-The present system depends on the tracking vessel's crew for recording of the movements of the fish. It obviously could be coupled to an automatic course recorder, yielding a permanent graph and tracing of the entire operation.

Recoverable Transmitters.-The present transmitters are quite expensive and become (so far) a total loss after use on a pelagic fish. If the transmitting part were given positive buoyancy and were fastened to the attachment part by water soluble glue or an electromagnet, it could be released from the fish after a predetermined period, with a good chance of recovery.

Attaching the Transmitter.-It was found that in the handling of the tuna, at least, it was more convenient to have several boats fishing and the tracking boat hovering nearby to come up to 
whichever boat hooked a fish. After the fish had been brought alongside and the line passed to the crew of the tracking boat, the transmitter was attached just as soon as the fish had quieted enough to make attachment possible. This was accomplished as shown in Plate II, by a quick thrust, which imbedded the four miniature "lily irons" with which the capsule was provided. The device was placed in the area shown so that no vital organs would be damaged. The pole on the end of which the capsule was attached was withdrawn.

\section{SUMMARY}

1. A system for tracking large (over 250 lbs.) fishes by sonar is described; it consists of a transmitter attached to the fish, a boat-borne receiver and a sensitive special sensor for use near the instruments' range limit.
2. The transmitter is supplied with 12 watts for about 150 hours from self-contained batteries which provide sonar pulses of 50 to 100 milliseconds every two seconds at $38 \mathrm{KC}$.

3. The receiver has two hydrophones mounted rigidly underwater and so placed and angled that the signal from them makes it possible to head the boat toward the transmitter-carrying fish, by means of the vessel's steering system.

4. A zero-centered meter and stereo earphones deliver the output from the receiver, which make tracking possible for distances of 1.5 to 2 miles, depending on the speed of the boat and the state of the sea.

5. Tests with sharks and tuna proved that it was fully practicable to follow such a transmitting fish by means of this system. 


\section{EXPLANATION OF THE PLATES}

\section{Plate I}

FIG. 1. The transmitter capsule ready for attaching to a fish. The sonic transducer is to the left.

FIG. 2. The submergible part of the two receiving transducers, imbedded in their sound-protective matrix.

FIG. 3. The shipboard end of the receiving system, showing both aural and optical indicators.
FIG. 4. The hand-held sonic detector of superior sensitivity for use in marginal areas.

FIG. 5. The boat used for tracking, showing the boom supporting the submerged sensors, ahead of the prow.

\section{Plate II}

FIG. 6. The manner in which the sonic capsule is attached to a fish.

FIG. 7. A tuna, just before release, showing the capsule attached. 


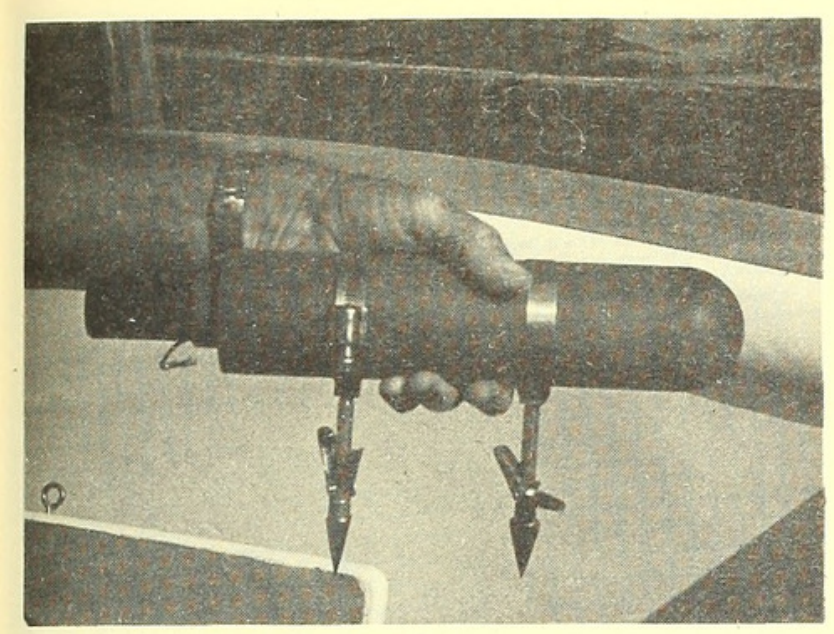

FIG. 1

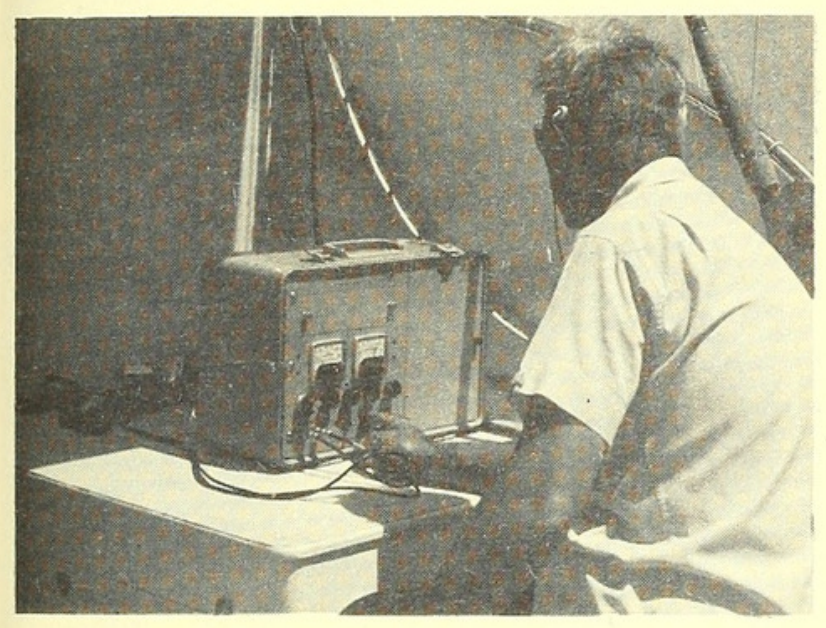

FIG. 3

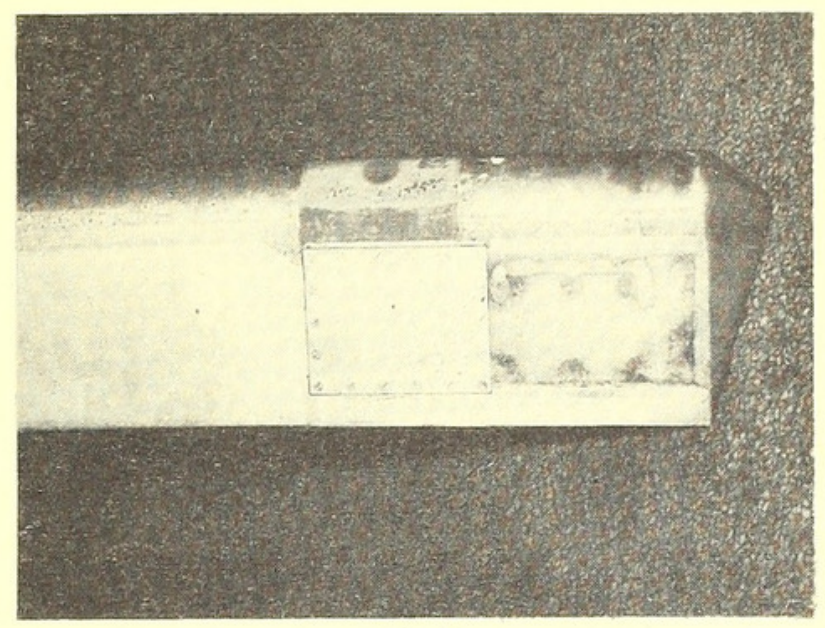

FIG. 2

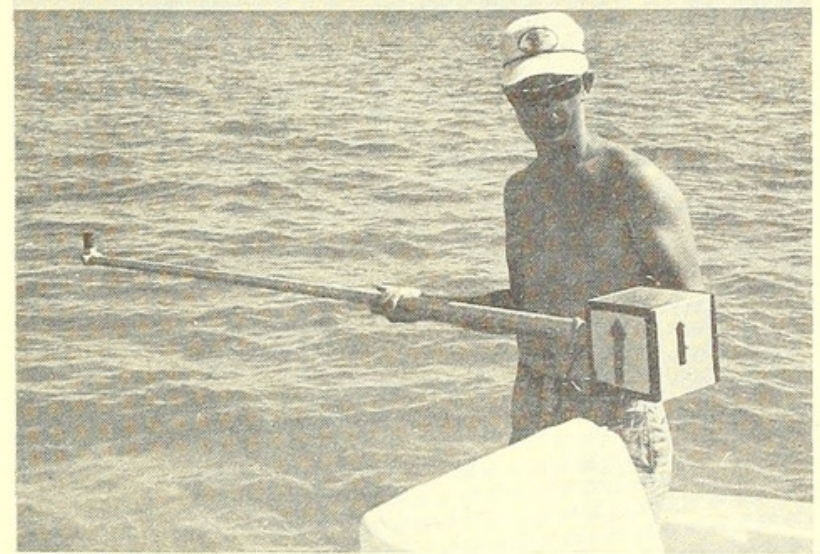

FIG. 4

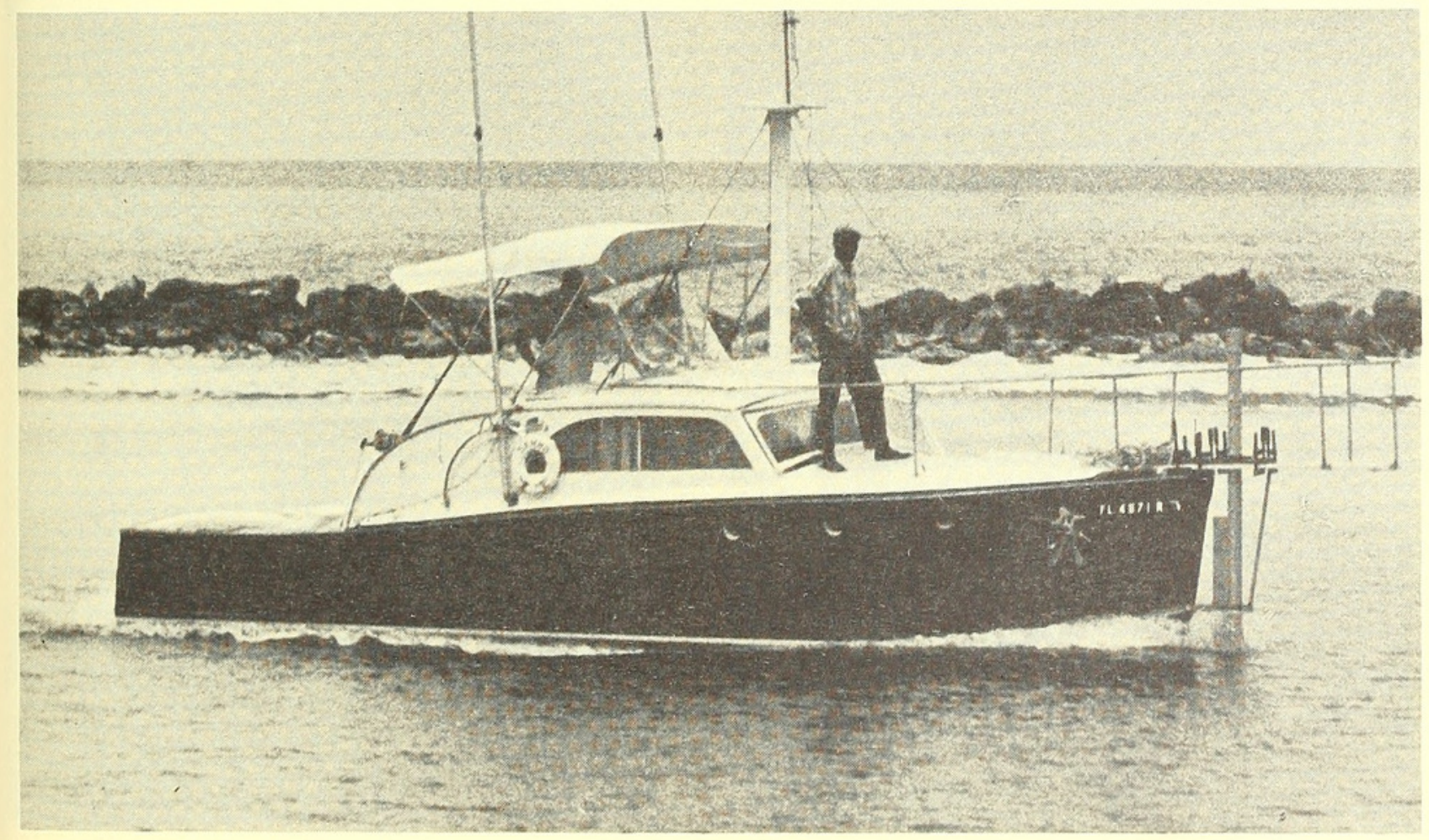

FIG. 5 


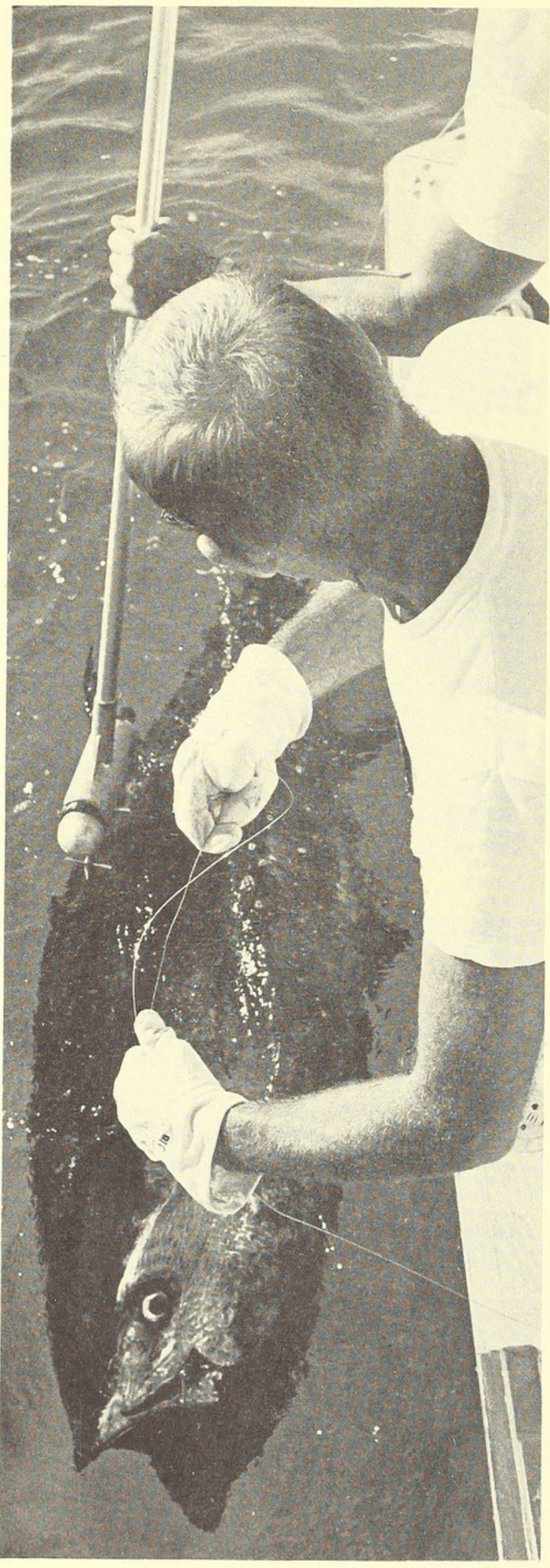

FIG. 6

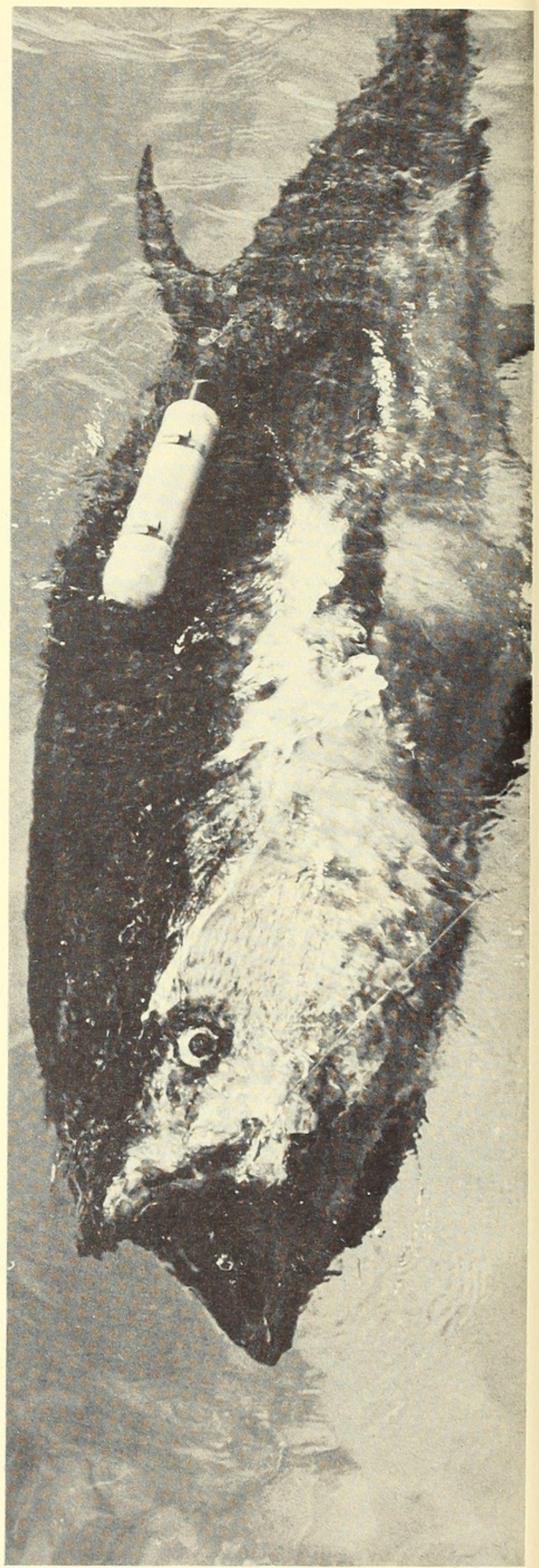

FIG. 7 


\section{$2 \mathrm{BHL}$ Biodiversity Heritage Library}

Bass, George A and Rascovich, Mark. 1965. "A device for the sonic tracking of large fishes." Zoologica: scientific contributions of the New York Zoological Society 50(8), 75-82. https://doi.org/10.5962/p.203272.

View This Item Online: https://www.biodiversitylibrary.org/item/208152

DOI: https://doi.org/10.5962/p.203272

Permalink: https://www.biodiversitylibrary.org/partpdf/203272

\section{Holding Institution}

Smithsonian Libraries

\section{Sponsored by}

Biodiversity Heritage Library

\section{Copyright \& Reuse}

Copyright Status: In Copyright. Digitized with the permission of the rights holder

Rights Holder: Wildlife Conservation Society

License: http://creativecommons.org/licenses/by-nc/3.0/

Rights: https://www.biodiversitylibrary.org/permissions/

This document was created from content at the Biodiversity Heritage Library, the world's largest open access digital library for biodiversity literature and archives. Visit BHL at https://www.biodiversitylibrary.org. 